\title{
SIN CORPUS NO HAY HISTORIA: LA RED CHARTA COMO UN PROYECTO DE EDICIÓN COMÚN
}

\author{
Elena Diez del Corral Areta \\ Université de Lausanne \\ elena.diezdelcorralareta@unil.ch
}

\author{
Leyre Martín Aizpuru \\ Universidad de Salamanca \\ leire.martin@usal.es
}

The aim of this paper is to present the CHARTA Net (Hispanic and American Corpus on the Web: Ancient Documents) to the scientific community that is not yet aware of its research purposes and its advantages regarding the editing and the subsequent philological analysis of Old and Classical Spanish documents. We begin by presenting the main characteristics of CHARTA, its aims, the research groups that take part in it, and its development from its origin to the present day. Then we describe the methodology that is currently being used, by explaining the triple presentation. We also include a description of the edition criteria that have been established and the problems that have arisen from them. An example of an edited document is provided. Finally, we comment on the current state of the project and the following steps to be taken.

Key words: CHARTA Net, edition of ancient documents, edition criteria

El objetivo de este trabajo es presentar la Red CHARTA (Corpus Hispánico y Americano En La Red: Textos Antiguos) a la comunidad científica que no conozca todavía sus propósitos investigadores y sus ventajas en lo que respecta a 
la edición y al posterior análisis filológico de documentos antiguos en español. En él se expone lo que es la Red CHARTA, señalando sus objetivos, los grupos de investigación que la integran y su trayectoria desde sus orígenes hasta la actualidad. Así mismo, se detalla la metodología que se emplea con la explicación de la triple presentación, los criterios de edición que se han establecido y las dificultades que se han presentado al formularlos. Se ofrece también un ejemplo concreto de un documento editado y se comenta el estado actual del proyecto y las tareas que quedan todavía por acometer.

Palabras clave: Red CHARTA, edición de textos antiguos, criterios de edición

\section{LA RED CHARTA}

La Red CHARTA ${ }^{1}$ es un proyecto de edición de un corpus de documentos antiguos en el que se aprovechan la metodología de la filología y los avances de la informática con el fin de publicar en Internet un corpus de textos y documentos antiguos de los siglos XII al XIX escritos en España e Hispanoamérica.

El origen de este proyecto se sitúa en una reunión celebrada en 2005, en Deusto, donde investigadores de las universidades de Alcalá, Deusto, Murcia, Valladolid, Las Palmas de Gran Canaria y del Consejo Superior de Investigaciones Científicas se reunieron para debatir sobre el aprovechamiento del lenguaje informático de marcación en las tareas de la edición digital. La falta de un estándar en el campo de la edición de textos antiguos motivó a estos investigadores a trabajar en conjunto con el ob-

\footnotetext{
1 <www.charta.es> [Consultado el 14 de febrero de 2014].
} 
jetivo de proponer unos criterios que pudieran ser válidos para toda la comunidad científica.

A partir de ese primer encuentro y a lo largo de numerosas reuniones -Alcalá de Henares, 2006; Murcia, 2006; Valladolid, 2007 y 2008; Sigüenza, 2010 y Madrid (CCHS-CSIC), 2012- los integrantes de este nuevo y creciente grupo ${ }^{2}$ han ido buscando la manera de satisfacer las necesidades científicas de todos aquellos que se acercan a un texto histórico. En la reunión de Alcalá de Henares se decidió que el sistema de edición más completo y satisfactorio es el de la triple presentación, esto es, una presentación que incluye una reproducción facsimilar, una transcripción paleográfica y una edición crítica. El segundo paso fundamental fue establecer una serie de criterios comunes para el trabajo con los diferentes textos y documentos históricos.

La presentación en público de esta iniciativa tuvo lugar en el primer congreso de la Red, celebrado en el Consejo Superior de Investigaciones Científicas (Madrid, noviembre de 2009), bajo el rótulo "Tradición e innovación: nuevas perspectivas para la edición y el estudio de documentos antiguos". En él, los miembros de los diferentes grupos de trabajo pusieron en común sus tareas en el campo de la edición y estudios lingüísticos. En septiembre de 2011, siguiendo el camino iniciado dos ańos atrás, se

2 En 2007, a los grupos fundadores citados se unieron las universidades de Los Andes, Complutense de Madrid, Gotemburgo, Islas Baleares, King's College, Neuchâtel, Padua y Salamanca. En 2011 se incorporaron otros grupos de investigación de las Universidades de Granada, La Rioja, Málaga, Nacional Autónoma de México y Tokio. En el año 2013, se han integrado dos grupos de investigación más procedentes de las Universidades de Navarra, Santiago de Compostela y Sevilla. Por último, en 2014 se ha sumado a la Red el grupo de Lausana. 
celebró el segundo congreso, esta vez en la Universidad de Neuchâtel (Suiza), que -como veremos en $\$ 1.2-$, supuso el inicio de una nueva etapa para la Red, con la acogida de nuevos integrantes.

El último congreso de la Red se celebró en junio del 2013 en la Universidad de Salamanca, en el cual se integraron dos grupos nuevos con la perspectiva de publicar en Internet, en el año 2014, el corpus desarrollado en los años pasados.

\subsection{Objetivos}

El principal objetivo de este grupo ha sido establecer una metodología común para la edición de textos, ya que hasta el momento han coexistido y coexisten diferentes criterios que atienden a los intereses dispares desde los que se acercan al texto los investigadores -historiadores, diplomáticos, paleógrafos, etc.-.

En segundo lugar, se ha realizado una propuesta de presentación gráfica para la transcripción paleográfica y la edición crítica, atendiendo a criterios filológico-lingüísticos rigurosos y homogéneos.

A continuación -y esta es la labor principal del momento actual-, se pretende elaborar un amplio corpus en red de fuentes documentales que abarque la variedad geográfica del español, tanto de España como de América, en un arco cronológico amplio y con muestras de textos pertenecientes a tradiciones discursivas muy dispares, todo ello valiéndose de las herramientas informáticas para el análisis lingüístico de los textos.

El cuidadoso trabajo de lectura y edición de los textos permite, en tercer lugar, llevar a cabo estudios de diferentes disciplinas interesadas 
por los textos antiguos, con la seguridad de manejar material original y fiable. ${ }^{3}$

\subsection{Los grupos que forman CHARTA}

Al día de hoy, la Red CHARTA está formada por un total de 22 grupos, cuyas labores y corpus manejados pasamos a describir a continuación:

- Grupo de la Universidad de Alcalá, dirigido por Pedro Sánchez-Prieto Borja, coordinador a su vez de la Red: está encargado de editar la documentación peninsular desde la época de orígenes hasta 1800, así como documentación americana de Bolivia, Paraguay y Centroamérica.

- Grupo del CSIC, dirigido por María Jesús Torrens Álvarez: trabaja con documentación medieval de monasterios burgaleses de los siglos XII-XVII.

- Grupo de la Universidad de Deusto, dirigido por Carmen Isasi: edita la documentación norteña, del País Vasco y Cantabria, del siglo XviI al XIX.

- Grupo de las Islas Baleares, dirigido por Andrés Enrique-Arias: está especializado en la documentación castellana escrita por catalanohablantes bilingües en Mallorca (1739-1833).

- Grupo de la Universidad de Murcia, dirigido por Pilar Díez de Revenga Torres: trabaja con documentos notariales de los siglos XIII-

3 Con esta metodología se evita la disparidad de criterios empleados en la edición de los textos y el mero volcado de colecciones documentales que caracterizan otros corpus como el conocido y ampliamente utilizado CORDE. 
XVIII producidos en Murcia y varios procesos inquisitoriales del siglo XVII e inventarios de bienes del siglo xviII.

- Grupo de la Universidad de Neuchâtel, dirigido por Juan Pedro Sánchez Méndez: se ocupa de la documentación de la Audiencia de Quito y de Panamá del siglo XVI hasta los primeros decenios del XIX (1550-1810).

- Grupo de las Palmas de Gran Canaria, dirigido por Rosa María González Monllor: prepara la edición de documentos de diversa tipología producidos en Canarias del siglo XVI al XviII.

- Grupo de la Universidad de Gotemburgo, dirigido por Ingmar Söhrman: edita cartas diplomáticas enviadas de Suecia a España del siglo XVII (1670-1673).

- Grupo de la Universidad de Salamanca, dirigido por María Nieves Sánchez González de Herrero: trabaja con documentos de cancillería castellana del siglo XIII; documentos medievales de Miranda de Ebro (Burgos); documentos medievales de la zona leonesa (monasterio de Santa María de Gradefes, monasterio de Santa María de Otero de las Dueñas, catedral de León, monasterio de Carrizo, monasterio de Sahagún).

- Grupo de la Universidad de Valladolid, dirigido por Micaela Carrera de la Red: se ocupa de la documentación americana de los siglos XVI-XIX de la isla La Española, actuales Haití y República Dominicana, documentos de la actual Colombia y documentos de Mérida (Venezuela, siglo XIx).

- Grupo de la Universidad de Los Andes, dirigido por Enrique Obediente: se encarga de editar documentos de diversa tipología pro- 
ducidos en la antigua Provincia de Mérida, tanto en algunas de sus ciudades como en la sede de la Real Audiencia (Santa Fé de Bogotá) de los siglos XVI-XVII.

- Grupo del Instituto Historia de la Lengua (Cilengua) y la Universidad de la Rioja (IHLyUR), dirigido por Marta Gómez Martínez: lleva a cabo la edición de documentación altorriojana de los siglos XVI-XVII (1512-1682), conservados en el Monasterio de Yuso de San Millán de la Cogolla (La Rioja).

- Grupo de la Universidad de Málaga, dirigido por Inés Carrasco Cantos: trabaja con documentación notarial de los siglos XV al XIX conservada en los archivos municipal, histórico provincial, catedralicio y diocesano de Málaga.

- Grupo de la Universidad de Granada, dirigido por Miguel Calderón Campos: edita declaraciones de testigos (pleitos criminales, probanzas, sumaria información), cartas e inventarios de bienes de 1492 a 1833 .

- Grupo de la Universidad Nacional Autónoma de México, dirigido por Beatriz Arias Álvarez: trabaja con documentos coloniales mexicanos de los siglos XVI, XVII, XVII y dos décadas del XIX.

- Grupo de la Universidad de Sevilla, dirigido por Lola Pons Rodríguez: se interesa por toda documentación de lamento escrita en primera persona que presenta la queja de un particular desde el español de orígenes hasta el siglo xIx. Para ello trabajan con textos conservados en el Archivo Histórico Provincial de Sevilla, el Archivo de Indias, el Archivo Histórico Nacional y el Archivo de Simancas.

- Grupo de la Universidad de Santiago de Compostela, dirigido por Ricardo Pichel Gotérrez: edita documentación gallega escrita en cas- 
tellano desde el siglo XIII hasta el XIX. Trabajan, por tanto, con documentos conservados en diferentes archivos históricos y catedralicios de la comunidad autónoma de Galicia.

- Grupo de la Universidad de Navarra, dirigido por Cristina Tabernero Sala: trabaja con documentos de diferentes tipologías, fechados entre los siglos XV y XIX y depositados en archivos privados de Navarra.

- Grupo de Lausana, dirigido por Mónica Castillo Lluch y Elena Diez del Corral Areta: edita documentación administrativa y genealógica (siglo xvi al xx) del Fondo Balbueno de la Bibliothèque Cantonale et Universitaire de Lausanne.

Además de los grupos encargados de editar los diferentes corpus, la Red cuenta con tres colaboraciones informáticas, de la Universidad Complutense, Bautista Horcajada, del King's College, Paul Spence y de la Universidad de Tokio, Hiroto Ueda, que serán fundamentales en la puesta en marcha del corpus online, con la aplicación de los lenguajes de marcación y etiquetas TEI. ${ }^{4}$

De la descripción realizada se puede observar que en la Red CHARTA se maneja un amplio y, sobre todo, variado corpus de textos. Variedad que afecta, en primer lugar, a la distribución geográfica -con la edición de documentos de diferentes puntos geográficos de España y América-; en segundo lugar, a la cronología, ya que los primeros textos que se editan pertenecen a la época de orígenes, siglo XII, y los últimos al siglo XIX; en tercer lugar, a la variedad lingüística, pues, además del castellano, se inclu-

\footnotetext{
4 <http://www.tei-c.org/index.xml> [Consultado el 14 de febrero de 2014].
} 
yen muestras bilingües catalano-castellanas emitidas en las islas Baleares y textos de Galicia escritos en espańol en los que pueden observarse ciertas interferencias con el gallego; y en cuarto lugar, a la tipología textual manejada: por un lado, fuentes documentales, como la documentación real de cancillería (privilegios, cartas plomadas, cartas abiertas), municipal, eclesiástica, testamentos, mandatos, ordenanzas e inventarios de bienes.

Se ofrece, por tanto, una gran variedad en la documentación, si bien al hablar de la representatividad del corpus es necesario ser prudentes pues, como cualquier otro corpus diasistemático, CHARTA no es un corpus figurativo total. En un artículo anterior sobre el grupo (Sánchez González de Herrero et al. 2013) ya se puso de manifiesto que ante el manejo de cualquier corpus es el usuario el que debe establecer sus propios parámetros de búsqueda -ya sea geográfica, cronológica, etc.- para "asegurar la proporcionalidad de la muestra”.

Por otro lado, este trabajo de edición ha sido facilitado por el resurgir que ha tenido el texto antiguo y con las mejores condiciones de acceso a los archivos, como se verá a continuación.

\section{Metodología de TRABAjo: CRITERIOS DE EDICióN}

Una vez expuestos los fundamentos, los orígenes y los miembros integrantes de la Red CHARTA es necesario detenernos en explicar el proceso metodológico que se ha ido forjando en los últimos años, tras prolongadas discusiones y reflexiones, con el fin de lograr los objetivos que se planteó el grupo CHARTA desde sus inicios. En este apartado se impone, en primer lugar, la necesidad de contextualizar el nacimiento de la Red CHARTA en 
un momento histórico en el que se produce un resurgimiento del interés por los textos documentales. A la explicación del porqué y del cómo se sucedieron estos acontecimientos se dedicará un primer subapartado -el $\$ 2.1$ -

En segundo lugar, se ha creído conveniente ofrecer la revisión de un conjunto de ediciones - tal y como cotejó el grupo CHARTA-, en busca de la mejor opción para editar los documentos archivísticos. El papel que juega el lector, por ejemplo, es imprescindible en la edición de textos, pues en la publicación de cualquier obra nunca hay que perder de vista al destinatario al que va dirigida. Por otro lado, los objetivos del investigador condicionan también su edición de los textos, por lo que disponemos de un conjunto de ediciones de una variada índole, tal y como se muestra en $\$ 2.2$.

Por último, y tras la exposición de las diversas opciones de edición que se nos presentan, se dedica el tercer subapartado - el $\$ 2.3-$ a ofrecer la propuesta de "edición múltiple" del grupo CHARTA. Los criterios de edición contemplan un acceso triple al documento a través de la reproducción facsimilar del documento, de la realización de una transcripción paleográfica y de la elaboración de una presentación crítica. Estos criterios, además, tienen cierto carácter universal y permiten la edición de textos muy variados tanto desde el punto de vista cronológico como tipológico, como se ha podido comprobar en la descripción del trabajo de edición de cada grupo.

\subsection{El resurgir del interés por el texto}

En los últimos años se ha producido un creciente interés por los textos documentales como una fuente primordial a tener en cuenta tanto en la investigación filológica como en la histórica. Esta nueva atención por el 
texto antiguo está vinculada, además, con los avances tecnológicos que se han ido (y se van) produciendo de manera vertiginosa en nuestra sociedad y que proporcionan nuevas herramientas metodológicas para el desarrollo y la mejora de las investigaciones científicas.

En la actualidad disponemos de nuevos procedimientos y técnicas de la información que nos permiten, por ejemplo, acceder a las fuentes manuscritas sin necesidad de desplazarnos hasta el archivo donde se custodian. La difusión del patrimonio histórico documental a través de Internet ha producido proyectos de gran envergadura como la creación de un Portal de Archivos Españoles (PARES), ${ }^{5}$ promovida por el Ministerio de Cultura, que ofrece un acceso libre y gratuito, no solo al investigador, sino a cualquier ciudadano interesado por las fuentes documentales que se conservan en los Archivos Españoles.

Como en toda gran empresa incipiente, queda todavía un gran camino por recorrer. La accesibilidad del documento en forma digital es todavía precaria en muchos archivos e inexistente en otros, por lo que merece una mayor atención y una mejora en sus infraestructuras (Diez del Corral 2012). Aun así, es innegable que el acceso a las fuentes documentales ha mejorado notablemente y que Internet ha brindado un soporte de difusión valiosísimo y poderoso que ha permitido incluso la creación de bibliotecas digitales que incorporan, en su mayoría, los facsímiles de las obras que se poseen.

En la lingüística, en concreto, y como consecuencia de estos avances, se originó una subdisciplina conocida como lingüistica del corpus que maneja

\footnotetext{
$5<$ http://pares.mcu.es> [Consultado el 14 de febrero de 2014].
} 
corpus mucho más extensos - por el interés científico que supone el recurso a ellos como una fuente empírica de datos- en relación a los que el lingüista o el filólogo estaba acostumbrado a trabajar.

En el presente trabajo no nos vamos a ocupar de sopesar las ventajas e inconvenientes de los avances tecnológicos, sino que nos centramos en presentar un proyecto científico riguroso que se ha propuesto la creación de un corpus textual en la Red con la ventaja de la uniformidad de criterios, combinando -como se ha mencionado anteriormente- la experiencia filológica tradicional en la edición de textos de muchos de sus integrantes con las nuevas herramientas que proporcionan los avances tecnológicos.

De ningún modo se pretende desestimar la edición en papel que, como todos sabemos, permite una lectura lineal y completa del texto, sino aprovechar las ventajas del soporte electrónico que nos ofrece otras posibilidades, no solo facilitando su acceso a cualquier persona, sino ofreciendo también una edición continua. Las correcciones en un formato electrónico pueden realizarse con mayor celeridad que en el tradicional papel, en el que la preparación de la publicación de una segunda edición implica una mayor inversión de tiempo.

\subsection{La coexistencia de distintos tipos de ediciones}

El estudio de las fuentes documentales puede abordarse desde enfoques muy dispares y con objetivos diversos. Así pues, el paleógrafo, el diplomatista o el especialista de cualquiera de las tradicionalmente llamadas "ciencias auxiliares" tendrá unas necesidades distintas de las que pueda tener, por ejemplo, un historiador o un filólogo. Las ediciones que busquen unos 
y otros variarán según sus necesidades. Al historiador, por ejemplo, le atrae el contenido del manuscrito y no suele prestar atención a la expresión verbal en la que se fija el filólogo o a los distintos tipos de escrituras que interesan al paleógrafo. Este último necesita una edición más respetuosa y fidedigna del diploma con todos sus rasgos, mientras que el historiador se suele conformar únicamente con una edición que no desvirtúe el contenido del manuscrito. Incluso podemos afirmar que dentro de una misma disciplina como la Lingüística, el interés por un tipo de edición concreto puede variar entre los diversos investigadores. El especialista en fonética y fonología, por ejemplo, necesitará una edición que cumpla unos requisitos quizá innecesarios o superfluos para el especialista en sintaxis o léxico.

$\mathrm{El}$ interés por las fuentes archivísticas es muy variado, por lo que para cualquier tipo de edición textual -y en verdad, para todo género de publicación- debe atenderse principalmente al objetivo del investigador-editor y a lo que se cree que pueda interesar al investigador-lector. El aprovechamiento de este último se verá condicionado por la edición con la que se tope $-\mathrm{y}$ dada la heterogeneidad de intereses, se publican ediciones de diversa índole-, pues la disparidad de soluciones y criterios le obligará a recorrer un camino nuevo cada vez que se enfrente a una de ellas.

Ante tal ausencia de homogeneidad se plantea la pregunta de si pueden proponerse unos criterios válidos para todas las orientaciones. ¿Cómo puede realizarse una edición que nos satisfaga a todos? ¿Qué requisitos debe tener para que cumpla todas nuestras necesidades? Tradicionalmente, cada investigador ha propuesto un modo de editar propio, aunque, en realidad, también existe una serie de intentos de unificar y de crear unos criterios entre los que cabe citar la obra de P. Sánchez-Prieto Borja, Cómo editar los 
textos medievales. Criterios para su presentación gráfica, dirigida a la edición de textos de la Edad Media o las conocidas normas de edición propuestas por la Escuela de Estudios Medievales en 1944: Normas de transcripción de textos $y$ documentos.

En contraposición con la investigación individual, el trabajo en equipo permite que se aúnen las experiencias de especialistas en la edición de textos en aras de elaborar unos criterios lo más acertado posibles para la edición de un variado y amplio conjunto de documentación. Ese ha sido el objetivo y la manera de actuar del grupo CHARTA, que se ha aventurado a acometer una empresa editorial de dimensiones considerables. Además, el uso de recursos electrónicos para la edición necesita de unos criterios comunes y ofrece posibilidades interesantes tales como la lematización de fenómenos que permite la distinción de formas aparentemente semejantes a primera vista.

La puesta en común de las experiencias editoriales de grupos de investigación a nivel internacional como los que integran el grupo CHARTA -ya explicitados en $\$ 1.2$ - ha dado su fruto en la propuesta que ofrecemos a continuación.

\subsection{La propuesta de CHARTA: una edición múltiple}

Si la Escuela de Estudios Medievales propuso unas normas a la hora de llevar a cabo cualquier edición de textos, el grupo CHARTA propone no unas normas, sino unos criterios de edición.

Estos criterios deben ajustarse al interés de un amplio grupo de investigadores y cubrir las expectativas de muchos lectores que necesiten 
desde una edición de gran rigor paleográfico -nos referimos, por ejemplo, a aquellas personas que estudien la historia de la escritura o la fonética histórica- hasta otra, cuyo interés resida únicamente en el contenido que exprese -como puede ser, como citábamos con anterioridad, el caso de un historiador-.

Para ello, la propuesta del grupo CHARTA consiste en ofrecer lo que se designa como una 'edición múltiple' que proporcione toda la información que los diversos intereses de los investigadores demandan. De esa manera, el grupo CHARTA propone una forma triple de edición para los textos -transcripción paleográfica, presentación crítica y reproducción facsimilar-frente a la edición única que suele realizarse, por ejemplo, para los textos literarios. ${ }^{6}$

El triple acceso permite la ampliación del alcance de esos textos, pues atrae el interés de investigadores de diferentes áreas, posibilitando estudios de carácter interdisciplinar.

En primer lugar, se ofrece una reproducción facsimilar del documento. El facsímil permite abordar estudios diplomáticos y paleográficos que serían inabordables a través de otro tipo de edición. Asimismo, su acceso permite también comprobar algunas dudas que nos puedan surgir al trabajar con las transcripciones, pues como en toda labor que se realiza y, a pesar del cuidado y esmero que se dedique, siempre pueden existir errores.

El segundo tipo de edición contempla la elaboración de una transcripción paleográfica. Esta -como bien indica su nombre- se lleva a cabo

6 Un corpus con triple presentación es el CODEA que puede consultarse en: <www.textoshispanicos.es> [Consultado el 14 de febrero de 2014] 
siguiendo unos criterios de gran rigor paleográfico. En ese sentido se pone de relieve el sistema gráfico del documento, lo que permite plantear la evaluación fonética de las grafías. Junto a ella, el facsímil se presenta como un complemento ideal para los interesados en la relación entre grafías y fonemas.

En tercer lugar, el grupo CHARTA ha considerado también la utilidad de ofrecer una presentación crítica del documento. Este tipo de edición o presentación facilita la lectura a un público más amplio en el que podrían comprenderse investigadores de disciplinas como la Historia o la Lingüística y dentro de esta última, especialistas interesados por el estudio de la morfología, de la sintaxis y del léxico.

Esta triple edición nos acerca al ideal de interrogar el documento en su integridad y además, tiene una aplicación particular en la edición digital, si bien también se ha ensayado previamente en el formato tradicional de papel en los siete volúmenes de la serie Textos para la historia del español (I: 1911; II: 1995; III: 2005; IV: 2005; V: 2010; VI: 2011; VII: 2012). ${ }^{7}$

Los criterios que presenta el grupo CHARTA son fruto de una reflexión prolongada entre todos los miembros y grupos de investigación que lo integran. La principal ventaja que presentan frente a los criterios individuales es que han sido largamente meditados y ensayados en la edición de textos variados tanto desde un punto de vista cronológico como desde un punto de vista tipológico.

7 El octavo volumen saldrá publicado en 2015: Nieves Sánchez González de Herrero (dir.), Clara Grande López, Ana Lobo Puga, Vicente Marcet Rodríguez, Leyre Martín Aizpuru y Raquel Sánchez Romo (en prensa): Textos para la historia del español VIII. Documentos medievales de Miranda de Ebro. 
Además, estos criterios presentan otro rasgo primordial que es su universalidad. Se ha intentado que los criterios sean válidos para todo el ámbito hispánico con el objetivo de poder editar la inmensa cantidad de series documentales que se custodian en los diferentes archivos de los países hispanohablantes. La validez de los criterios que ofrece la Red CHARTA podría incluso ampliarse a otros textos en lenguas romances. La idea de la edición múltiple es perfectamente aplicable y recomendable para la edición de cualquier documento y los criterios de la transcripción paleográfica también servirían, aunque quizá se necesitaría -al igual que para la presentación crítica- una revisión integral de todos ellos para ver su adecuación a los textos que se quieren editar y, quizá, la propuesta de criterios específicos para cada lengua e incluso para cada época histórica.

No obstante, es una ampliación de los objetivos que presentamos como una posibilidad en un futuro. La Red CHARTA tiene primero otras tareas más inmediatas por realizar - de las que se hablará en $\$ 3-$, si bien no se descarta por completo esta idea.

En cuanto al acceso a los criterios de edición, se puede hacer tanto en formato electrónico, a través de la página web del grupo, como en formato papel, gracias a la publicación de su coordinador Pedro Sánchez-Prieto Borja (2011) en Cilengua: La edición de textos españoles medievales y clásicos. Criterios de presentación gráfica.

Consideramos y ofrecemos estos criterios como una base que cualquier editor de textos en el ámbito hispánico -o incluso en el románico- puede tomar como referencia, a pesar de que en última instancia él mismo pueda exponer y tomar sus propias soluciones. 


\section{EJEMPLO DE EDICIÓN DE UN DOCUMENTO}

A continuación, y como ejemplo de todo lo expuesto previamente, les incluimos la edición múltiple de un documento específico: en primer lugar, hemos incorporado el facsímil en color, en segundo término, la transcripción paleográfica de ese texto y por último, la presentación crítica. El documento, de 1396, es un documento inédito transcrito por María Jesús Torrens, coordinadora del grupo de investigación del CSIC. ${ }^{8}$

\subsection{Reproducción facsimilar}

Imagen 1. Documento de 1396. Reproducción facsimilar

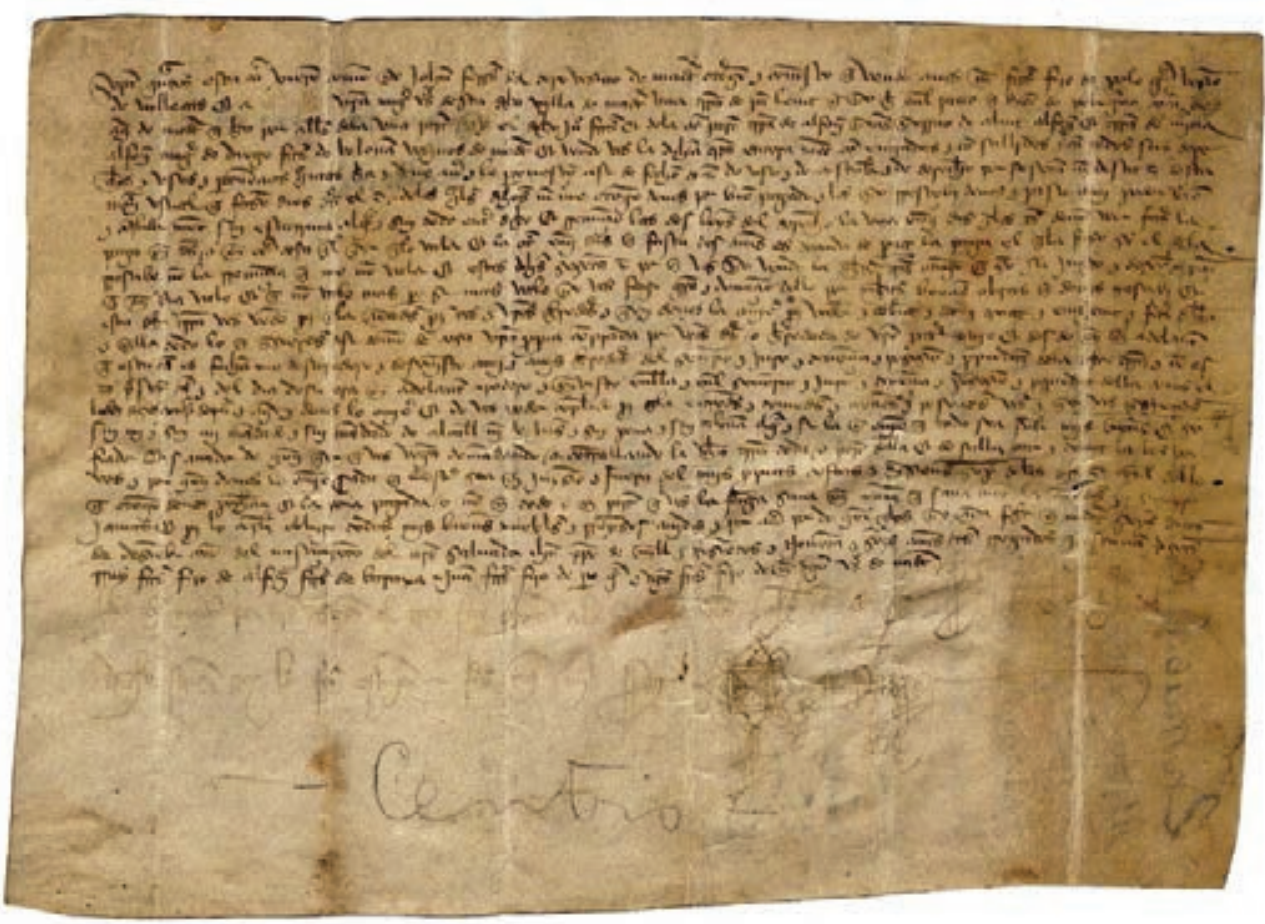

8 Un estudio más detallado sobre este documento puede verse en un artículo de su transcriptora (Torrens Álvarez 2012). 


\subsection{Transcripción paleográfica}

Sepan quantos esta carta vieren como yo Johan ferrandez del toro vezino de madrit otorgo \& connosco que vendo auos martin ferrandez fijo de polo garcia vezino $\left.\right|^{2}$ de vallecas Et a [borrado: maria gonçalez] vuestra muger vezinos desta dicha vjlla de madrit vna tierra de pan leuar que yo he enel pauo que dizen pelegrina cerca de $\left.\right|^{3}$ aqui de madrit que ha por alledannos dela vna parte [borrado: yo] el dicho joan ferrandez Et dela otra parte tierra de alfonso yannez yerrno de aluar alfonso Et tierra de marjna $\left.\right|^{4}$ alfonso muger de diego ferrandez de bolonna vezjnos de madrit Et vendo vos la dicha tierra entera mente con entradas $\&$ con salljdas $\&$ con $n$ todos sus dere $\left.\right|^{5}$ chos $\&$ vsos $\&$ pertenencias quantos ha $\&$ deue auer $\&$ le pertenesçen asi de fecho como de vso $\&$ de costu $n$ bre $\&$ de derecho por sesenta marauedis desta moneda desta $\left.\right|^{6}$ moneda vsual que fazen diez dineros el marauedi delos quales dichos marauedis me otorgo deuos por bien pagado $\&$ los yo rresçebj deuos $\&$ pasa amj poder bien $\left.\right|^{7} \&$ conplida mente sin escatjma alguna $\&$ sin todo entre dicho Et rrenunçio las dos leyes del derecho la vna enque diz quelos testigos deuen veer fazer la $\left.\right|^{8}$ paga en dineros o en otra cosa qual quier quelo vala Et la otra enque diz que fasta dos annos es deuido de prouer la paga el quela faze sy el quela $\left.\right|^{9}$ rrescibe no $n$ la rrenunçia que me non vala Et estos dichos sesenta marauedis por que vos yo vendo la dicha tierra otorgo que son su justo $\&$ derecho preçio $\mid{ }^{10}$ que oy dia vale Et que non vale mas pero si mas vale yo vos fago gracia $\&$ donaçion dello por muchas buenas obras que deuos rresçibj Et $\left.\right|^{11}$ esta dicha tierra vos vendo para quela ayades para vos \& vuestros herederos \& quien deuos la oujere para vender $\&$ canbiar $\&$ dar $\&$ trocar $\&$ enagenar $\&$ fazer 
della $\left.\right|^{12} \&$ enella todo lo que quesierdes asi como de cosa vuestra propia conprada por vuestros dineros o heredada de vuestro patrimonjo Et desde oy en adelante $\left.\right|^{13}$ que esta carta es fecha me desapodero $\&$ desenujsto amj $\&$ amjs herederos del sen $n$ orio $\&$ propiedat dela dicha tierra $\&$ con es $\mid{ }^{14} \mathrm{ta}$ presente carta $\&$ del dia desu era en adelante apodero $\&$ envisto enella $\&$ enel sen $n$ orio $\&$ juro $\&$ tenençia $\&$ posesion $\&$ propiedat della auos el $\left.\right|^{15}$ $1^{* * *}$ dichos conpradores $\&$ aquien deuos lo oujere Et do vos poder conplido para quela entredes $\&$ tomedes $\&$ ayades $\&$ poseades vos $\&$ quien vos quisierdes $\left.\right|^{16} \sin \mathrm{mj} \& \sin \mathrm{mj}$ mandado $\& \sin$ mandado de alcalle $\mathrm{nj} n$ de Juez $\&$ sin pena $\&$ sin calonna alguna $\&$ si la y oujere que toda sea sobre mjs bienes Et so $\left.\right|^{17}$ fiador Et sanador de quien quier que vos venga demandando o contrallando la dicha tierra toda o parte della Et de sallir otor $\&$ tomar la boz por $\left.\right|^{18}$ vos $\&$ por quien deuos lo oujere Cada que menester sea en juyzio o fuera del amjs propias costas \& mjsiones sopena delas dich ${ }^{* *}$ monedas con el doblo $\left.\right|^{19}$ que otorgo deuos pechar Et la pena pagada o non en todo o en parte que vos la faga sana en manera que sana mente la ayades para sienpre ${ }^{20}$ jamas Et para lo conplir obligo todos mjs bienes muebles \& rrayzes aujdos \& por auer por do quier quelos yo aya fecha en madrit seys dias $\left.\right|^{21}$ de dezienbre an $n$ o del nasçimjento del nuestro saluador ihesu xpcristo de mjll \& trezientos \& Nouenta $\&$ seys annos testes rrogados que estauan presentes $\left.\right|^{22}$ rruy ferrandez fijo de alfonso de baraxa $\&$ juan ferrandez fijo de pero garcia $\&$ diego ferrandez fijo de diego vezinos de madrit [mano 2] [***] $\left.\right|^{23}$ blico en madrit por nuestro sennor el rrey fuy presente a lo que $\left.{ }^{[* *}\right]$ conlos dichos testigos $\left.\mathrm{Et}\left[{ }^{* * *}\right]\right|^{24} \mathrm{~d}\left[{ }^{* * *}\right]$ ruy lo fiz escriujr \& fiz aqui mio ssig[signo] no [firma] 


\subsection{Presentación critica}

Sepan cuantos esta carta vieren como yo Joán Ferrández del Toro, vezino de Madrit, otorgo e coñosco que vendo a vós Martín Ferrández, fijo de Polo García, vezino $\left.\right|^{2}$ de Vallecas, e a vuestra muger, vezinos d'esta dicha villa de Madrit, una tierra de pan levar que yo he en el pavo que dizen Pelegrina, cerca de $\left.\right|^{3}$ aquí de Madrit, que ha por alledaños de la una parte el dicho Joán Ferrández, e de la otra parte tierra de Alfonso Yáñez, yerno de Álvar Alfonso, e tierra de Marina $\mid{ }^{4}$ Alfonso, muger de Diego Ferrández de Bolońa, vezinos de Madrit. E véndovos la dicha tierra enteramente, con entradas e con sallidas, e con todos sus dere $\left.\right|^{5}$ chos e usos e pertenencias, cuantos ha e deve aver e le pertenecen, así de fecho como de uso e de costumbre e de derecho, por sesenta maravedís d'esta $\left.\right|^{6}$ moneda usual que fazen diez dineros el maravedí, de los cuales dichos maravedís me otorgo de vós por bien pagado, e los yo recebí de vós e passa a mi poder bien $\Gamma^{7}$ e complidamente, sin escatima alguna e sin todo entredicho. E renuncio las dos leyes del derecho, la una en que diz que los testigos deven veer fazer la $\left.\right|^{8}$ paga en dineros o en otra cosa cualquier que lo vala, e la otra en que diz que fasta dos ańos es devido de prover la paga el que la faze si el que la $\left.\right|^{9}$ recibe non la renuncia, que me non vala. E estos dichos sesenta maravedís por que vos yo vendo la dicha tierra otorgo que son su justo e derecho precio $\mid{ }^{10}$ que hoy día vale e que non vale más, pero si más vale yo vos fago gracia e donación d'ello por muchas buenas obras que de vós recibí. $\left.\mathrm{E}\right|^{11}$ esta dicha tierra vos vendo para que la ayades para vós e vuestros herederos e quien de vós la oviere para vender, e cambiar, e dar, e trocar, e enagenar e fazer d'ella $\left.\right|^{12}$ e en ella todo lo que quesierdes, así como de cosa vuestra propia comprada por vuestros dineros 
o heredada de vuestro patrimonio. E desde hoy en adelante $\mid{ }^{13}$ que esta carta es fecha me desapodero e desenvisto a mí e a mis herederos del señorío e propiedat de la dicha tierra, e con es $\mid{ }^{14}$ ta presente carta e del día de su era en adelante apodero e envisto en ella e en el señorío, e juro, e tenencia, e posesión e propiedat d'ella a vós $\left.\right|^{15}$ los dichos compradores e a quien de vós lo oviere, e dóvos poder complido para que la entredes e tomedes, e ayades e poseades vós e quien vós quisierdes $\left.\right|^{16} \sin$ mí e sin mi mandado e sin mandado de alcalle nin de juez, e sin pena e sin caloña alguna, e si la ý oviere que toda sea sobre mis bienes. E só $\left.\right|^{17}$ fiador e sanador de quienquier que vos venga demandando o contrallando la dicha tierra, toda o parte d'ella, e de sallir otor e tomar la boz por vós $\left.\right|^{18}$ e por quien de vós lo oviere cada que menester sea, en juizio o fuera d'él, a mis propias costas e misiones, so pena de las dichas monedas con el doblo $\left.\right|^{19}$ que otorgo de vos pechar. E la pena pagada o non, en todo o en parte, que vos la faga sana en manera que sanamente la ayades para siempre $\mid{ }^{20}$ jamás. E para lo complir obligo todos mis bienes muebles e raízes, avidos e por aver, por doquier que los yo aya. Fecha en Madrit, seis días ${ }^{21}$ de deziembre, año del nacimiento del nuestro salvador Jesucristo de mill e trezientos e noventa e seis años. Testes rogados que estavan presentes: $\left.\right|^{22}$ Ruy Ferrández, fijo de Alfonso de Baraxa, e Juan Ferrández, fijo de Pero García, e Diego Ferrández, fijo de Diego, vezinos de Madrit. <...> pú| $\left.\right|^{23}$ blico en Madrit por nuestro señor el rey fui presente a lo que con los dichos testigos e $\left.\right|^{24}<\ldots>$ lo fiz escrivir e fiz aquí mio signo.

\section{Estado aCtUAL DEL PROYECTO y TAREAS FUTURAS}

Actualmente, el objetivo principal e inmediato del proyecto es la primera publicación de un número cuantioso de documentación en la Red. Hasta 
el momento, y desde el nacimiento de CHARTA, todos los grupos de investigación han dedicado sus esfuerzos a la labor transcriptora, teniendo siempre presente la aplicación y el cumplimiento de los criterios acordados. Cada documento ha sido revisado por una o dos personas diferentes del encargado de la transcripción paleográfica y la presentación crítica. De ese modo, se ofrecerá un trabajo serio y riguroso de edición, acompañado del facsímil del manuscrito -siempre que los archivos concedan un permiso- por si el lector quisiera consultarlo al mismo tiempo.

El año 2014 será, por tanto, cuando se publique el primer corpus de CHARTA. A partir de entonces los documentos serán presentados en diferentes fases y se prevé la edición de nuevos manuscritos al menos anualmente, así como las correcciones de los ya editados. La publicación de los documentos se realizará a través de una plataforma en la Red. A partir de ella y directamente enlazada con la página web del grupo se podrá acceder a la edición de todos los manuscritos que se vayan colgando.

Asimismo y de forma paralela, un grupo formado por miembros del King's College y de las Universidades de Alcalá, Deusto y Salamanca han trabajado en cómo aplicar las nuevas tecnologías a la edición de textos. El resultado es la elaboración de una "Guía para editar textos CHARTA según el estándar TEI: una propuesta". ${ }^{9}$ El principal objetivo de este trabajo es representar los Criterios de edición de la Red CHARTA mediante un lenguaje de etiquetado (XML-TEI) y, en última instancia, "crear un modelo "tecno-humanístico" enfocado fundamentalmente a la edición

9 La publicación está disponible en una nueva sección de la página web de la Red CHARTA: http://www.charta.es/investigacion/charta-tei/. 
de fuentes documentales, que al mismo tiempo podría ser aplicable o adaptable a otro tipo de documentos" (Spence et al. 2012:474). A pesar de la publicación de este material, la investigación en este campo no está ni mucho menos concluida ya que en estas primeras fases de trabajo se han ido anotando diferentes aspectos que deberán ser mejorados a fin de que la labor de edición digital sea más asequible para los investigadores (Martín Aizpuru, en prensa $\$ 2$. Proyecto CHARTA en TEI).

Por otra parte, en los últimos años, el profesor Hiroto Ueda de la Universidad de Tokio ha mostrado a los miembros de la Red nuevas herramientas con las que realizar búsquedas y formas de aplicar la estadística a los estudios históricos (2013a, 2013b, 2014).

Este trabajo es posible gracias a que todos los miembros del grupo se reúnen, al menos, dos veces al año para discutir posibles dudas y problemas. Asimismo, para solventar los aspectos conflictivos que puedan surgir en la edición de textos, existen grupos específicos de expertos de cada período cronológico que se encargan de discutir, reflexionar y llegar a un consenso con el ánimo de que exista uniformidad y homogeneidad en las soluciones adoptadas.

En definitiva, la Red CHARTA es un proyecto en ebullición y con inquietudes que pretende implantar una nueva manera de trabajar en el campo de la edición y en el estudio de textos antiguos del que en un futuro muy próximo esperamos unos resultados positivos para toda la comunidad científica y, en especial, para aquellos interesados en la filología, en la lingüística y en la historia de la lengua. 


\section{BibLIOGRAFÍA}

Díaz Moreno, Rocío (ed.), 2011. Textos para la Historia del español VI. Archivo histórico provincial de Guadalajara. Alcalá de Henares: Servicio de publicaciones Universidad de Alcalá.

Carrasco Cantos, Inés (dir.), 2012. Textos para la historia del español VII. Archivo Histórico Provincial de Málaga. Alcalá de Henares: Servicio de Publicaciones Universidad de Alcalá.

Diez del Corral Areta, Elena, 2012. "Encrucijada de ediciones: la accesibilidad a los textos documentales". Versants 59 (3), pp. 35-44.

Escuela de estudios medievales, 1944. Normas de transcripción de textos y documentos. Madrid: CSIC.

Martín Aizpuru, Leyre, en prensa. "Algunos recursos informáticos al servicio de la edición de textos: la edición en XML-TEI". Actas del XII Congreso Internacional de la Asociación de Jóvenes Investigadores de Historiografia e Historia de la Lengua Española (Universidad de Padua, 2-4 de mayo de 2012).

Paredes García, Florentino, 2005. Textos para la Historia del español III. Archivo Municipal de Alcalá de Henares. Alcalá de Henares: Universidad de Alcalá.

Paredes García, Florentino, 2010. Textos para la Historia del español V. Archivo municipal de Daganzo. Alcalá de Henares: Servicio de publicaciones Universidad de Alcalá.

Sánchez González de Herrero, Nieves, Juan Sánchez Méndez, Ingmar Söhrman y María Jesús Torrens Álvarez, 2013. "La Red Charta: objetivos y método”. En Emili Casanova Herrero y Cesareo Calvo Rigual 
(eds.), Actas del XXVI Congreso Internacional de Lingüistica y de Filología Románicas (Universidad de Valencia, 6-11 de septiembre de 2010), tomo VII. Berlín: De Gruyter Mouton, pp. 263-274.

Sánchez-Prieto Borja, Pedro (coord.), 1991. Textos para la historia del español, I. Reproducción facsimil, transcripción paleográfica, presentación crítica y comentario lingüistico de documentos medievales y de los siglos XVI y XVII. Alcalá de Henares: Universidad de Alcalá.

Sánchez-Prieto Borja, Pedro (coord.), 1995. Textos para la historia del español, II. Archivo Municipal de Guadalajara. Alcalá de Henares: Universidad de Alcalá.

Sánchez-Prieto Borja, Pedro, 1998. Cómo editar los textos medievales. Criterios para su presentación gráfica. Madrid: Arco-Libros.

Sánchez-Prieto Borja, Pedro y Ana Flores Ramírez, 2005. Textos para la Historia del español, IV. Archivo Regional de la Comunidad de Madrid. Alcalá de Henares: Universidad de Alcalá.

Sánchez-Prieto Borja, Pedro, 2011. La edición de textos españoles medievales y clásicos. Criterios de presentación gráfica. San Millán de la Cogolla: Cilengua.

Spence, Paul, Carmen Isasi, Elena Pierazzo e Irene Vicente, 2012. "Cruzando la brecha: marcación digital con criterios filológicos". En María Jesús Torrens Álvarez y Pedro Sánchez-Prieto Borja (eds.), Nuevas perspectivas para la edición y el estudio de documentos hispánicos antiguos. Berna: Peter Lang, pp. 465-483.

Isasi, Carmen (coord.), Ana Lobo Puga, Leyre Martín Aizpuru, Santiago Pérez Isasi, Elena Pierazzo y Paul Spence (coords.)/Con el apoyo de varios colaboradores, reconocidos en el apartado de Agradecimientos, 
en prensa. "Guía para editar textos CHARTA según el estándar TEI: una propuesta". Red CHARTA.

Torrens Álvarez, María Jesús, 2012. "Los Documentos Lingüísticos del Centro de Estudios Históricos”. En María Jesús Torrens Álvarez y Pedro Sánchez-Prieto Borja (eds.), Nuevas perspectivas para la edición y el estudio de documentos hispánicos antiguos. Berna: Peter Lang, pp. 233-252.

Ueda, Hiroto, 2013a. "La función de la tilde en la grafía abreviada $\mathrm{n}<\mathrm{n}>$ del español medieval. Evidencias en los documentos notariales castellanos del siglo XIII al Xv", Cuadernos del Instituto de Historia de la Lengua, Año 4, Num. 8, pp. 343-360.

Ueda, Hiroto, 2013b. "Pautas y frecuencias grafotácticas del español medieval. Presentación de métodos y observaciones de documentos notariales". Comunicación realizada en el Tercer Congreso Internacional Tradición e Innovación: nuevas perspectivas para la edición, la investigación y el estudio de documentos antiguos (Universidad de Salamanca, 5-7 de junio de 2013).

Ueda, Hiroto, 2014. "Grafías dobles palatales en los documentos notariales del siglo XIII al Xv; Sus implicaciones fonológicas y el origen de la letra española eñe”. En Instituto Cervantes de Tokio (ed.), Actas del Congreso Internacional sobre el español y la cultura hispánica. Instituto Cervantes de Tokio (Instituto Cervantes de Tokio, 1-3 de octubre de 2013), pp. 200-214. 
3 I 4 Elena Diez del Corral y Leyre Martín CLECM 2-2014

REFERENCIAS EN LÍNEA:

www.charta.es

http://pares.mcu.es

http://www.tei-c.org/index.xml

www.textoshispanicos.es 